\title{
e-Business Model to Optimise Sales through Digital Marketing in a Peruvian Company
}

\author{
Misael Lazo-Amado, Leoncio Cueva-Ruiz, Laberiano Andrade-Arenas \\ Facultad de Ciencias e Ingeniería \\ Universidad de Ciencias y Humanidades
}

\begin{abstract}
The COVID-19 pandemic has affected the Peruvian market, generating a great loss in sales in Peruvian companies. The objective of the research is to develop a model to optimize sales with the use of digital marketing in a Peruvian company, the chosen methodology is DesingScrum, which is a hybrid of Scrum and Desing Thinking, with 10 phases (empathize, define. It has 10 phases (empathise, define, ideate, planning meeting, sprint backlog, daily meeting, sprint review, sprint retrospective sprint, prototype and testing) and the MarvelApp tool was used to create the prototype. The results are obtained after the completion of the review of each sprint, showing in detail how it was progressing in each sprint, and through the retrospective evaluated the development of the project for the realization of continuous improvement in the next product. Further prototype was made, with the application MarvelApp, which shows the model of e-business. Then testing was done through a survey that customers gave their opinions about the prototype and finally the digital marketing proposal was made by a model, which explains the interconnected tools to attract new customers. The conclusion is the construction of the digital marketing model according to the needs of the context to improve the sales of the company through e-business.
\end{abstract}

Keywords-Design thinking; desingScrum methodology; digital marketing; e-Business; scrum

\section{INTRODUCTION}

The trade and economic impact of the pandemic on large and small businesses and organisations around the world has had an impact on their financial statements, and Pakistan's analysis indicates that 184 MIPYMES (small and mediumsized enterprises), $83 \%$, did not have a strategic plan in place to deal with the impact of the pandemic [1], MIPYMES were severely affected and face several problems such as reduced sales, supply chain disruption, decreased demand and financial problems [2].

In Latin America, the Argentinean country had been dragging along different economic problems before the pandemic began, generating the final blow to the economic and commercial crisis, as its currency began to devalue more than it should have, increasing the price of products [3]. Which President Alberto Fernandez had to take as a threat to Covid19 , where he addressed a message to the nation on 19 March 2020 [4]. Announcing a decree of compulsory isolation, he had to implement this measure so that there would not be an increase in positive cases of coronavirus.

Companies were hit hard economically and commercially by the instability of Covid-19. Peru suffered a hard blow in the coast, highlands and jungle. Then there was an attempt to adopt social distancing and restrictions on access to markets, which began to generate uncertainty in the purchase and sale of companies and organisations [5].As a clear example, when the pandemic started, people started to buy more products, generating a commercial and economic impact, which led to inflation in food products, transport, among others. In order for companies not to go bankrupt, the state had to designate a small bonus "ReactivaPeru" to help micro and large companies, this bonus was only going to be designated to all companies that were up to date in their tax payments or were registered with the National Superintendence of Customs and Tax Administration.

Then, according to the analysis of the problems of different countries of the world, it indicates a similar problem in the company Domínguez in Peru, which is the object of study, since the pandemic is the main problem, obtaining a great loss of potential and economic clients. We also identified that the importance of having a strategic plan to combat the pandemic in commercial matters is a priority.

The objective is to carry out an e-Business modelling to optimise sales through digital marketing in a Peruvian company.

This research work will allow the development of new ideas, contributing to the improvement of business in the Peruvian state, to the point of guiding businessmen to use e-business in their companies, whether they are MYPES or PYMES, allowing the optimisation of their virtual sales safely to the point that they can be recognised at national, departmental or district level. Taking into account that digital marketing will help to have a better positioning in the virtual market, while the E-commerce will be able to make any type of online purchase, having a better transparency towards their consumers.

\section{Literature REVIEW}

In these times of pandemic of covid-19 have increased virtual shops and digital marketing, as there are a variety of free or paid platforms for this implementation. Taking into account in this pandemic there have been different financial cases that have affected micro and large companies, which have been lowering their sales by the COVID-19 which did not have a contingency plan to be able to support their sales of their products.

It should also be pointed out that there was a decreasing demand for their sales, since at the beginning and even at the present time of the pandemic they have to comply with the sanitary norms decreed by the Peruvian government. For this reason, researchers are analysing and implementing new 
measures or strategies to maintain and increase their financial status. The financial problem in the pandemic has been affecting the majority of micro, medium and large companies, where they have had to implement a contingency plan to create different techniques to deal with this problem by means of. The multiple discriminant analysis (MDA), the binary regression that would come to be a logistic analysis these 2 techniques have to have a greater efficiency and security that have been applied at international level [6]. It is taken into account that $22 \%$ of companies implement e-commerce through B2C (Business-to-consumer) helping the supplier to reach the customer or end consumer, in order to have a greater reach to customers, applying some marketing strategies such as online marketing and social networks. Which have been benefiting large companies, rather than micro or medium enterprises applying the B2C strategy along with digital marketing [7]. It consists of 2 important states, massiveness and personification allowing to approach the customer through advertisements, by means of liking, priority, benefit, etc. [8]. Allowing for lowcost promotion of products to the customer.

Digital marketing has different problems at the time of structuring within the company. For which a solution emerged that consists of a set of ideas between the people in charge of advertising where different activities will be planned to learn, currently there are several independent companies that are dedicated to marketing and forget to plan the overall approach to develop [8].

On the other hand [9], an analysis is made where companies implement e-business in order to increase their sales in times of pandemic, however digital marketing strategies can improve e-commerce and has proven to be an effective method therefore [10], mentions that digital marketing tools allow to reach the target of companies, being the best strategy to satisfy the consumer.

Digital marketing is used to increase sales in an MYPE, being an effective $95 \%$ in sales, as well as the digital marketing strategy is supported in social networks, websites as it is able to attract many users and be visited continuously [11].

The e-commerce has been growing day by day, facilitating at the moment of carrying out the daily activities helping to create new business models. The e-commerce trying more of the purchase, sale and services of the products that the company has, where the participants would come to do (consumer, salesman, mediator and commercial partners), some advantages that it has is at the moment of making a selection specific offers by means of the low costs of the products towards the market, to have a greater facility and security in the communication of the supplier and the client. One of the disadvantages of e-commerce is that it does not have a social aspect which makes it similar to a classic online shop and this can affect the level of the company through its sales of its products [12].

E-commerce has increased due to covid-19 as consumers were afraid of getting infected, which is why they were forced to shop online [13].

Analyses of various research papers where the authors show that large or small companies engaged in trade contain financial problems as in this pandemic reduced their sales by $85 \%$. That is why they were forced to carry out various strategies to generate more sales concluding that the success of e-commerce will continue to be one of the best online platforms to meet the needs of the consumer, so in the field of digital marketing as it will be responsible for increasing new potential customers.

\section{Methodology}

In our methodology we used Design Thinking and Scrum to implement the e-business, this methodology is called DesignScrum and has 10 stages (Empathise, Define, Ideate, Planning Meeting, Sprint Backlog, Daily Meeting, Sprint Review, Sprint Retrospective, Prototype, Testing).

\section{A. Design Thinking}

Design Thinking can be applied in different sectors and is one of the most demanded methodologies by companies, it has 5 stages (empathise, define, devise, prototype and test) as shown in Fig. 1 [14].

\section{DESIGN THINKING}

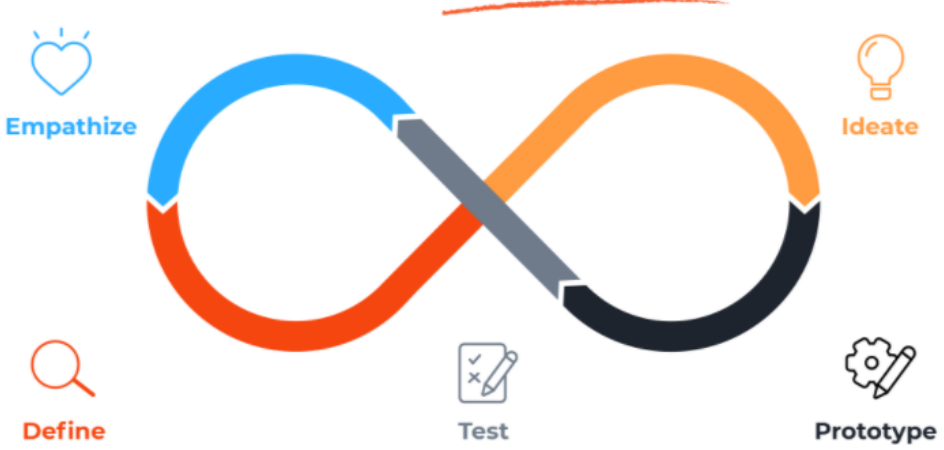

Fig. 1. Methodology Desing Thinking.

\section{B. Scrum}

The Scrum methodology is nowadays the most widely used methodology for project management in all companies for the development of web or desktop systems [15], The project is based on 3 important fundamentals that would make transparency, control and adaptation, guaranteeing us with a quality product [16]. It starts from the start date of the project, explaining its objectives and so that they can facilitate the designated work team [17], obtaining a product list. Then a product backlog will be made, this process helps to be able to manage the work team, finally a feedback will have to be made, so that it can be checked if the project is following all the corresponding step, to generate a quality product, as shown in Fig. 2 [18].

\section{Phases of the Hybrid Methodology}

The hybrid methodology called Desing Scrum, which is a combination of Design Thinking and Scrum, is explained in Fig. 3 indicating the phases to be used for the development of the e-business. 


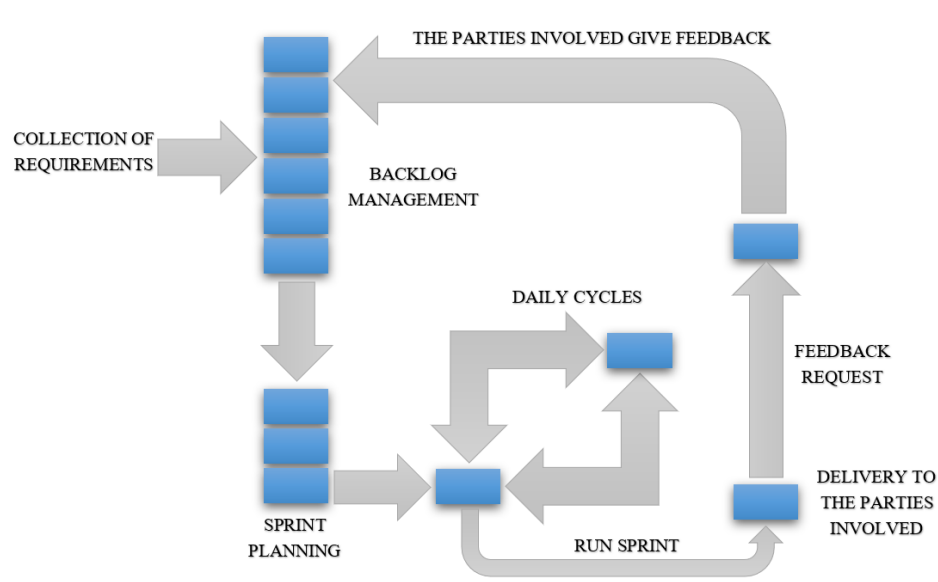

Fig. 2. Methodology Scrum.

1) Empathise: Empathy is the initial stage of the design thinking methodology, this will be in charge of knowing the needs of the users through surveys and interviews [19], allowing the designer to understand the problems of those involved.

2) Define: Once the needs of the users are known, the problem is defined [20]. The working team will be in charge of prioritising the most relevant problem of the users.

3) Ideate: At this stage, creativity and innovation will be developed, a variety of ideas will be developed to solve the users' problems [21]. The team will be in charge of choosing the ideal solution .

4) Planning Meeting: In this stage a set of requirements and user story will be defined to identify the functionality of the system where they will be grouped into a backlog [22].

5) Sprint Backlog: The sprint backlog is a set of tasks or user story where the development team divides up the sprint to have a better development [23]. Sprint backlogs are deliverables that maintain a delivery date, allowing for orderly work.

6) Daily Meeting: The working team will have to meet to see each other to clarify the work they have done [24]. This meeting should not last more than 15 minutes, in the meeting they can discuss what is going to be done, what the next meeting will be about, among other things.

7) Sprint Review: There will be a review of the overall sprint performance taking into account that each sprint will take 4 hours to review [25].

8) Sprint Retrospective: This process will be identified once all sprints have been completed and reviewed [26], allowing new ideas to be added to the completed sprints so that they do not generate any problems for the product .

9) Prototype: Finishing with the previous process which is the Sprint retrospective, here we will show the final prototype once all the necessary data has been obtained [27].

10 Testing: In this process it will be possible to carry out the necessary tests to see how the product works, with the aim of being able to improve if there are any faults. [28].

\section{Development of the Hybrid Methodology}

This part explains the development of the stages of the hybrid methodology.

1) Empathise: At this stage, potential customers are surveyed and asked whether they are comfortable with face-toface sales using the Google form tool.

Table I shows the questions (Q1 to Q5) that will be answered by potential customers, in which they are asked about comfort and attention in sales in 2021.

\section{TABLE I. SALES IN 2021 IN PERU-LIMA}

\begin{tabular}{|l|l|}
\hline \multicolumn{2}{|c|}{ Questions } \\
\hline ID & Questions \\
\hline Q1 & Do you have long queues when shopping? \\
\hline Q2 & $\begin{array}{l}\text { How many purchases do you make during the } \\
\text { month? }\end{array}$ \\
\hline Q3 & From which district of Lima are you located? \\
\hline Q4 & How long does it take to receive your products? \\
\hline Q5 & $\begin{array}{l}\text { How long does it take you to pay for your pur- } \\
\text { chases? }\end{array}$ \\
\hline
\end{tabular}

2) Define: According to the questions in the first stage survey, Table II identifies the problems of their sales from Q1 to Q5 and shows the responses of the customers who took the survey.

TABLE II. CUSTOMER RESPONSE TO THE SURVEY

\begin{tabular}{|l|l|}
\hline \multicolumn{2}{|c|}{ Answers } \\
\hline ID & Answers \\
\hline Q1 & $\begin{array}{l}75.7 \% \text { of customers indicate that they queue for a } \\
\text { long time. }\end{array}$ \\
\hline Q2 & $\begin{array}{l}48.6 \% \text { of customers indicate that they make 40 or } \\
\text { more purchases. }\end{array}$ \\
\hline Q3 & $\begin{array}{l}\text { In the Olivos district indicates that there are more } \\
\text { customers. }\end{array}$ \\
\hline Q4 & $\begin{array}{l}72.9 \% \text { of customers indicate that there is a delay } \\
\text { in receiving their products. }\end{array}$ \\
\hline Q5 & $\begin{array}{l}74.3 \% \text { of customers say their payment procedure } \\
\text { is slow }\end{array}$ \\
\hline
\end{tabular}

All these data were elaborated in August and September 2021. The answers were given according to the questionnaire sent to the customers of the Dominguez company, where $75.7 \%$ of the customers make their purchases. But, they have to wait in long queues, where the majority place their orders from 40 to more, the district where they place the largest number of orders is Los Olivos, with $72.9 \%$ of customers saying that their orders take a long time to reach their respective destinations and $74.3 \%$ take a long time to pay for their order.

3) Ideate: According to the problems identified in the define stage, the development team (T1, T2 and T3) proposes to devise an innovative solution, for which it needs to describe the possible solutions and then estimate the best solution by points from 1 to 20, as shown in Table III.

a) S1: The development team identified a solution which is to realise an e-business system to optimise sales where 59 points were estimated.

b) S2: In the second solution, new advertising strategies are proposed to attract new customers, with an estimated 43 points.

c) S3: In the third solution, a new payment system was devised to reduce traffic, with an estimated 49 points. 


\section{HYBRID METHODOLOGY: DESIGN SCRUM}

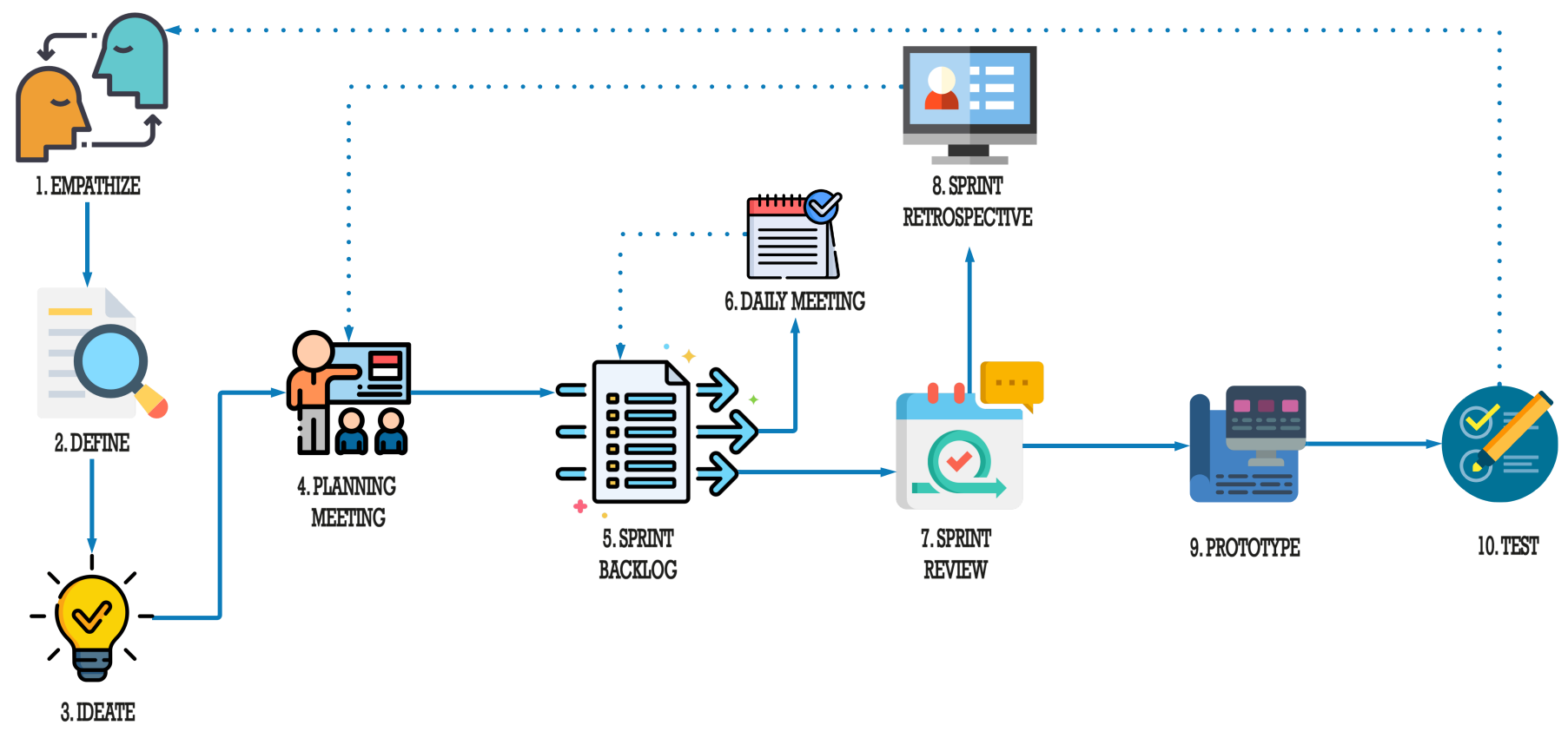

Fig. 3. Methodology DesingScrum.

d) S4: In the fourth solution, a product delivery system was devised for rapid dispatch where 39 points were estimated.

e) S5: In the fifth solution, the idea was to implement a local system for sales where 48 points were estimated.

\section{TABLE III. SCORING IDEAS}

\begin{tabular}{|l|c|c|l|l|}
\hline \multicolumn{5}{|c|}{ Punctuation of the Ideas } \\
\hline \multicolumn{1}{|c|}{ Solutions } & T1 & T2 & T3 & Total \\
\hline $\begin{array}{l}\text { S1- Realise an e-business sys- } \\
\text { tem to optimise sales. }\end{array}$ & 19 & 19 & 18 & 56 \\
\hline $\begin{array}{l}\text { S2- Create new advertising } \\
\text { strategies to generate more } \\
\text { customers. }\end{array}$ & 15 & 15 & 13 & 43 \\
\hline $\begin{array}{l}\text { S3- Implement a new payment } \\
\text { system to reduce traffic. }\end{array}$ & 15 & 16 & 18 & 49 \\
\hline $\begin{array}{l}\text { S4- Implement a product de- } \\
\text { livery system for rapid dis- } \\
\text { patch. }\end{array}$ & 15 & 13 & 11 & 39 \\
\hline $\begin{array}{l}\text { S5- Make a local system for } \\
\text { making sales. }\end{array}$ & 16 & 16 & 16 & 48 \\
\hline
\end{tabular}

4) Planning Meeting: This process will involve the team in identifying all user stories (H1 to H12) for product development, as shown in Table IV.

5) Sprint Backlog: In this process, the sprint backlog is explained, where the 12 user stories with 4 sprints are obtained, then the planing poker was carried out, where the cards were identified to measure the difficulty of each user story, and the estimated time of each sprint was identified [29].

The very small tasks are the fastest difficulties to develop, while the small tasks fall into the difficulty of very easy and intermediate level, the medium tasks would be of intermediate
TABLE IV. REQUIREMENTS

\begin{tabular}{|c|c|}
\hline \multicolumn{2}{|r|}{ USER STORIES } \\
\hline ID & DESCRIPTION \\
\hline 1- H1 & $\begin{array}{l}\text { The user will have to register a new account } \\
\text { (email, password) to log in to the application. }\end{array}$ \\
\hline 2- H2 & $\begin{array}{l}\text { The user will need an email address and password } \\
\text { to } \log \text { in to the application. }\end{array}$ \\
\hline 3- H3 & $\begin{array}{l}\text { The user will have a profile to fill in the corre- } \\
\text { sponding data (name, surname, type of document, } \\
\text { document, date of birth, name, email, telephone, } \\
\text { address, credit card). }\end{array}$ \\
\hline 4- H4 & $\begin{array}{l}\text { The user will have his or her password retriever } \\
\text { if he or she forgets it. }\end{array}$ \\
\hline 5- H5 & $\begin{array}{l}\text { The user will have an option of my purchases } \\
\text { where he/she will be able to have the purchases } \\
\text { to observe the purchases that he/she is going to } \\
\text { make. }\end{array}$ \\
\hline 6- H6 & $\begin{array}{l}\text { The user will have a catalogue to view the prod- } \\
\text { ucts they wish to buy. }\end{array}$ \\
\hline 7- H7 & $\begin{array}{l}\text { The user will be able to select a product and will } \\
\text { be able to order the required quantity. }\end{array}$ \\
\hline 8- H8 & $\begin{array}{l}\text { The user will be able to create a suggested list } \\
\text { where he/she can put the products he/she wants to } \\
\text { buy in the future. }\end{array}$ \\
\hline 9- H9 & $\begin{array}{l}\text { The user will have a search engine to find the } \\
\text { product found on the site. }\end{array}$ \\
\hline 10- H10 & $\begin{array}{l}\text { The user will have his shopping cart where he will } \\
\text { be able to buy his products. }\end{array}$ \\
\hline 11- H11 & $\begin{array}{l}\text { The user will have a help option, should he/she } \\
\text { have any doubts or queries. }\end{array}$ \\
\hline 12- H12 & $\begin{array}{l}\text { The user will be able to log out if they no longer } \\
\text { wish to shop on the site. }\end{array}$ \\
\hline
\end{tabular}

difficulty, as well as the large tasks that are the part where it would take more to have a concrete approach at the time of development; the large tasks would be a more structured process for its development, the invaluable task would be when 
TABLE V. SPRINT BACKLOG

\begin{tabular}{|c|c|c|c|}
\hline \multicolumn{4}{|c|}{ SPRINT BACKLOG } \\
\hline ID & Time & Difficulty Level & Sprint \\
\hline H1 & 4 days & $1 / 2$ Very small task & \\
\hline $\mathrm{H} 2$ & 5 days & 1 Small task & Sprint 1 \\
\hline H3 & 5 days & 2 Small task & \\
\hline $\mathrm{H} 4$ & 6 days & 3 Small task & \\
\hline H5 & 15 days & $\begin{array}{l}100 \text { Time for a break, bigger } \\
\text { tasks }\end{array}$ & \\
\hline H6 & 7 days & 5 Medium-sized tasks & Sprint 2 \\
\hline $\mathrm{H} 7$ & 8 days & 8 Medium-sized tasks & \\
\hline H8 & 8 days & 13 Medium-sized tasks & \\
\hline H9 & 8 days & 13 Medium-sized tasks & Sprint 3 \\
\hline H10 & 12 days & 40 Time for a break, big tasks & \\
\hline H11 & 8 days & 8 Medium-sized tasks & Sprint 4 \\
\hline H12 & 7 days & 5 Medium-sized tasks & \\
\hline
\end{tabular}

there is no specific date for its development, the huge task would be the most difficult difficulty as it requires a complete analysis for the development of the product. The sprint backlog is shown in Table V.

TABLE VI. SPRINT PLANNING

\begin{tabular}{|l|l|}
\hline \multicolumn{2}{|c|}{ Sprint Planning } \\
\hline SPRINT & DIAS \\
\hline Sprint 1 & 20 days \\
\hline Sprint 2 & 30 days \\
\hline Sprint 3 & 28 days \\
\hline Sprint 4 & 15 days \\
\hline TOTAL & 93 days \\
\hline
\end{tabular}

In Table VI it indicates the Sprint Planning where it indicates the total time of each sprint, as well as that the product will be finished in 3 months and 3 days.

In Fig. 4 you can see the cards that will be implemented to perform the planning poker this will help to facilitate the level of difficulty. They would be very small task. Small task, medium task, big task. Bigger task, invaluable task, huge task and time for a break.

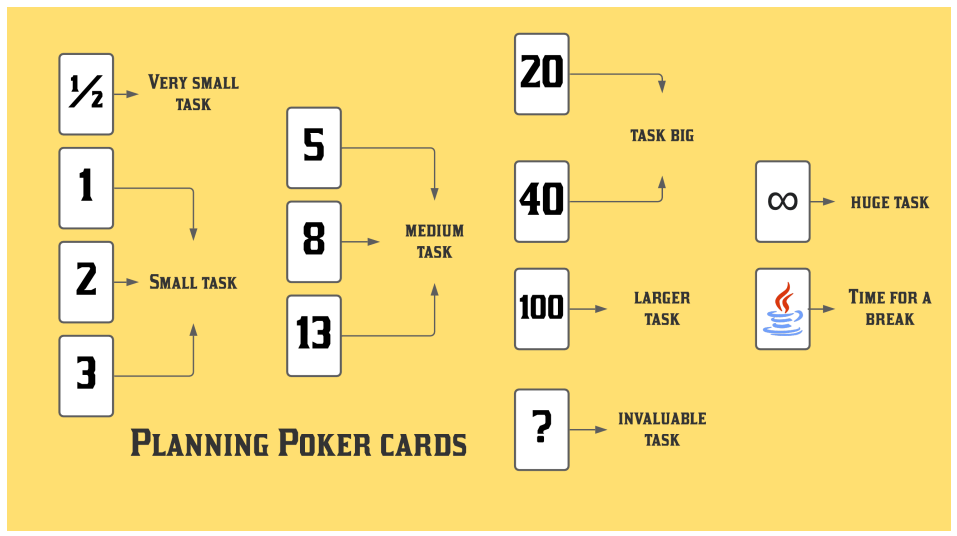

Fig. 4. Planning Poker.

It will show the 4 Sprint with their user stories that will be developed for the prototype operation.

a) Sprint 1 (H1): As shown in Fig. 5 it will be developed so that the user can register using the email and password, this will take an estimated time of 4 days to implement having a small task difficulty. b) Sprint 1 (H2): As shown in Fig. 5 it will be developed so that the user can $\log$ in to the application using the email and password that have been registered; this user story will have an estimated time of 5 days with a small task difficulty.

c) Sprint 1 (H3): As can be seen in Fig. 5, it will be developed so that the user can edit a profile, this will be used to put the corresponding data. This user story will take 5 days counting on the small task difficulty.

d) Sprint 1 (H4): As shown in Fig. 5, the password can be retrieved if the correct password is forgotten or not remembered, with an estimated time of 6 days with a low task difficulty.

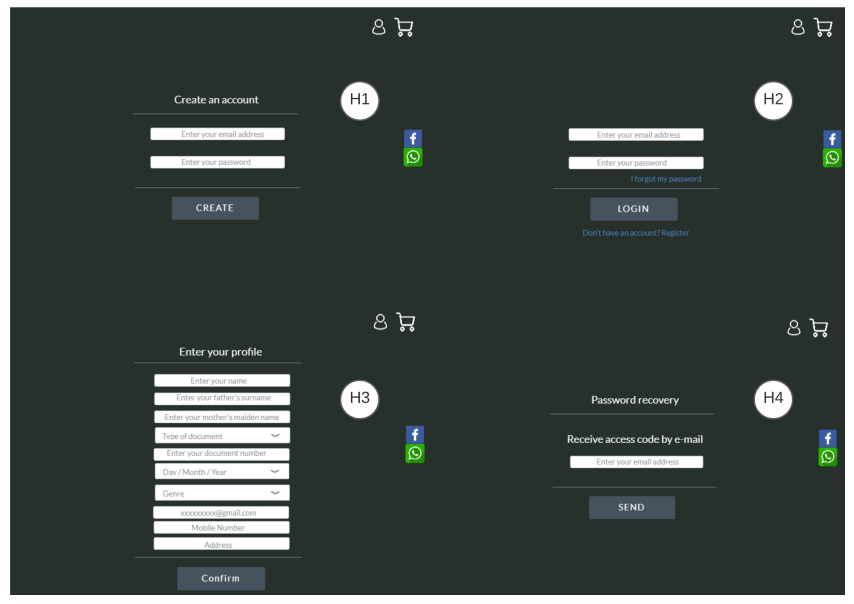

Fig. 5. Sprint 1.

e) Sprint 2 (H5): As shown in Fig. 6 you will have the option of catalogue where you will be able to see all the products with their corresponding categories, this user story will have an estimated time of 15 days. It will have 2 difficulties, the first difficulty will take a short break to see how far it has progressed and if everything is working properly, then continue with the difficulty of larger tasks for their respective development.

f) Sprint 2 (H6): As shown in Fig. 6, the user will have the option to see all the products they selected from the catalogue in their shopping cart, for this user story it is estimated a time of 7 days for its development with the difficulty of medium task.

g) Sprint 2 (H7): As shown in Fig. 6, the user will be able to select his product to order the necessary quantity he wants, either per unit or per box, and will have an estimated time of 8 days for its development, which will have the difficulty of a medium-sized task.

h) Sprint 3 (H8): As shown in Fig. 7, the user will have a shopping list in the future, this will allow the user to save the product in his list until he decides to buy it, this user story will have an estimated time of 8 days for its development, taking into account the medium difficulty of the task.

i) Sprint 3 (H9): As shown in Fig. 7, the user will have a search engine to find the product by name or category, with an estimated time of 8 days for its respective development, with a medium task difficulty. 


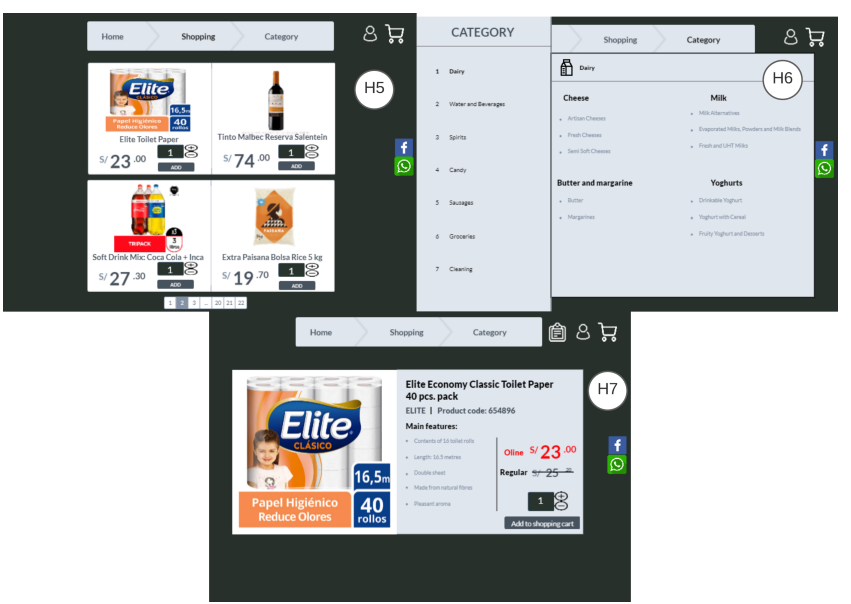

Fig. 6. Sprint 2.

j) Sprint 3 (H10): As can be seen in Fig. 7, the user will be able to make a purchase using the shopping cart once he has made or has chosen the selected product together with the corresponding quantity, he will have an estimated time of 12 days for its development. The first is to have a short break to see how far the user has progressed and if everything is working correctly, in order to be able to move on to the next difficulty, which would be the big task of user story 10.

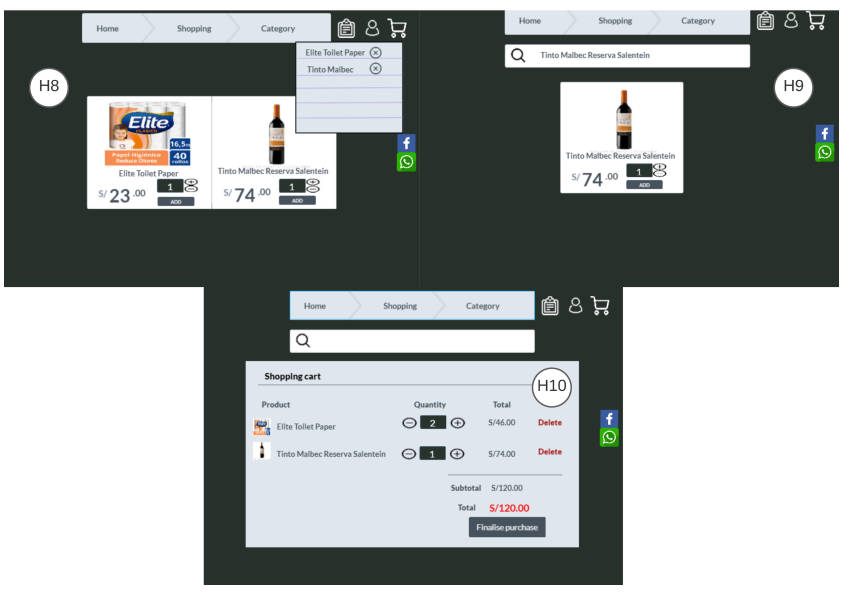

Fig. 7. Sprint 3.

k) Sprint 4 (H11): As shown in Fig. 8, the user will have the option of a wizard, where he/she can ask for help if he/she has any problem when purchasing or any difficulty in the system, this user story will have an estimated time of 8 days for its development. It will have the difficulty of medium task.

l) Sprint 4 (H12): As can be seen in Fig. 8, the user will be able to $\log$ out once the purchase has been made, and will have an estimated time of 7 days for its development. Counting on the medium task difficulty.

6) Daily meeting: In this process, a daily meeting will be held, allowing the team to meet every 20, 30, 28 and 15 days together with the scrum master, in order to improve teamwork. Allowing us to ask the following questions What did they do?

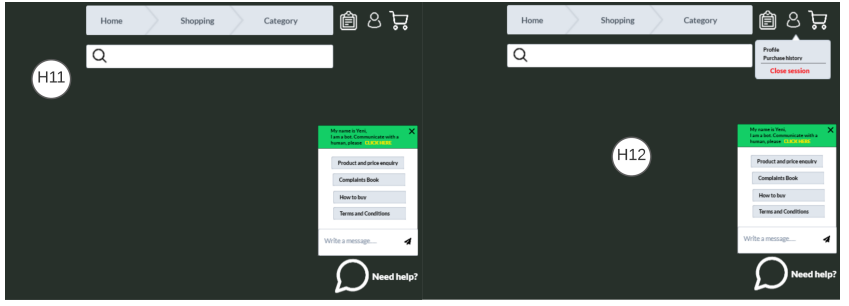

Fig. 8. Sprint 4.

What impediments did they face? Who worked on the project?

\section{Results AND Discussions}

In this chapter we will continue to show the next remaining stages, showing as a result the reviews of each Sprint, retrospective reviews, final prototype, the implementation of the questions towards the prototype, counting the respective answers and finally proposing the use of digital marketing.

\section{A. Sprint Review}

At the end of each Sprint, a review is carried out by the work team, this will take 3 to 4 hours of evaluation. The product owner is in charge of explaining so that it is accepted. After showing the users or attendees a comment is made to determine any changes or improvements to the product. At the end of the evaluation continues with the next Sprint, also, at the end of all the Sprint will move to the next stage [30].

a) Sprint 1: In Fig. 9 it indicates the revision of sprint 1, being presented by the Product Owner in which he indicates the start of the procedure on the estimated date of 16 August 2021, ending on 05 September 2021. It is also considered an accepted sprint.

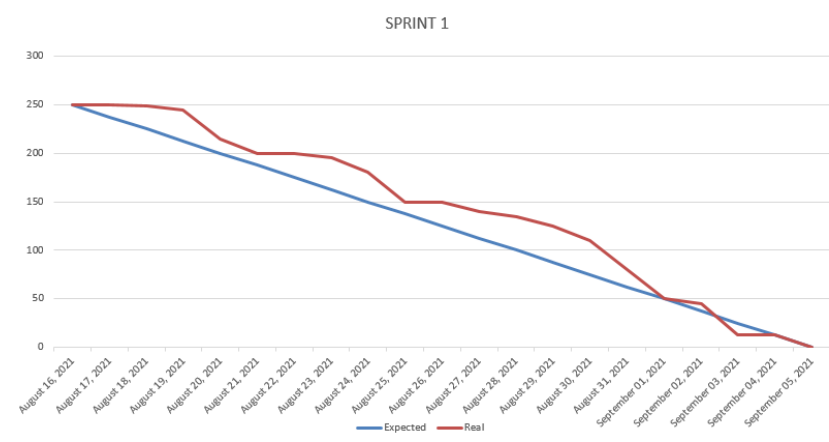

Fig. 9. Burdown Chart from Sprint 1.

b) Sprint 2: In Fig. 10 it indicates the revision of Sprint 2, being presented by the Product Owner in which he indicates the start of the procedure on the estimated date of 06 September 2021, ending on 06 October 2021. It is also considered an accepted sprint.

c) Sprint 3: In Fig. 11 it indicates the revision of sprint 3 , being presented by the Product Owner in which he indicates the start of the procedure on the estimated date of 07 October 2021, ending on 04 November 2021. It is also considered an accepted sprint. 


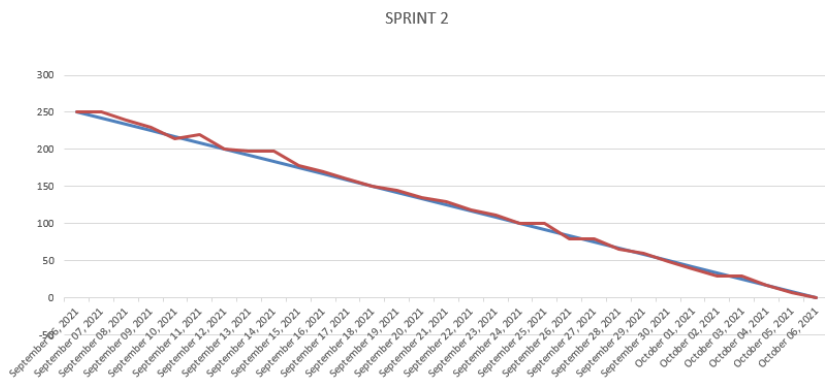

Fig. 10. Burndown Chart from Sprint 2.

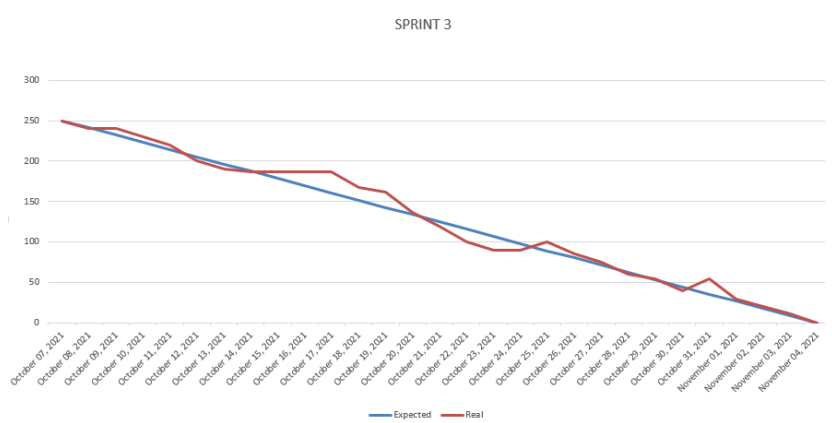

Fig. 11. Burndown Chart from Sprint 3.

d) Sprint 4: In Fig. 12 it indicates the revision of Sprint 4, being presented by the Product Owner in which he indicates the start of the procedure on the estimated date of 05 November 2021, ending on 20 November 2021. It is also considered an accepted sprint.

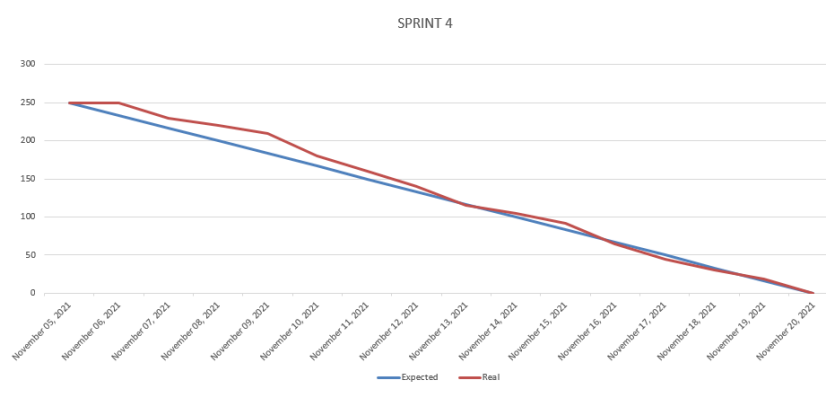

Fig. 12. Burndown Chart from Sprint 4.

\section{B. Retrospective Review}

In this stage, an evaluation of the process is carried out by the scrum master as shown in Table VII, convening a meeting with the Product Owner and the Work Team. This will be used to optimise the next product, for which the scrum master will ask: What did we do well, what can we improve and what should we stop doing?

a) R1: Meet the deadlines set for each sprint.

b) R2: Reduce sprint time to obtain a quick solution for the user.
TABLE VII. RETROSPECTIVE REVIEW

\begin{tabular}{|l|l|l|}
\hline \multicolumn{3}{|c|}{ RETROSPECTIVE REVIEW } \\
\hline Scrum master & Questions & Answers \\
\hline \multirow{3}{*}{ Scrum master 1 } & 1. What did we do right? & R1 \\
& 2. What can we improve? & R2 \\
& 3. What should we stop doing? & R3 \\
\hline
\end{tabular}

c) R3: Identify user stories with a single person.

\section{Prototype}

At this stage, a prototype was made and elaborated by MarvelApp application, this will be the mock-up for potential customers to give their opinion about it, as shown in Fig. 13.

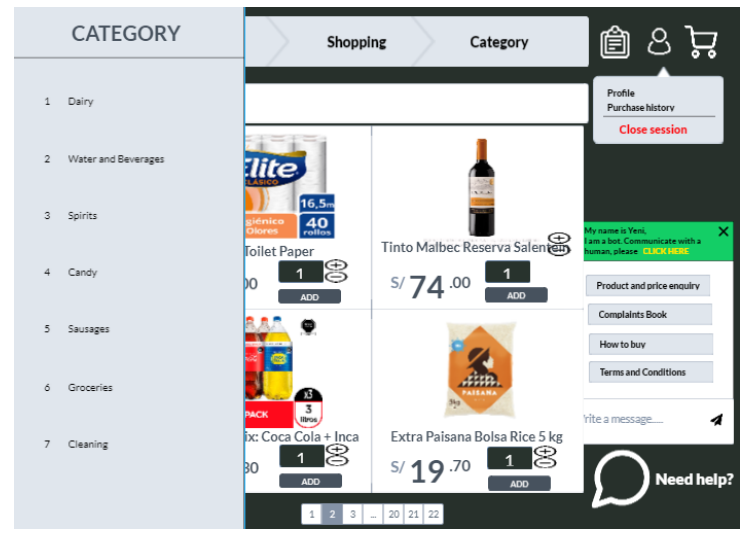

Fig. 13. Final Prototype.

\section{Testing}

In this final stage the questions and answers of the prototype will be shown to the customers.

1) Testing questions: A survey of 5 questions about the prototype (QP1 to QP5) was conducted, the customers will give their opinion about it, as shown in Table VIII.

TABLE VIII. PRototyPE SySTEM SURVEY

\begin{tabular}{|l|l|}
\hline \multicolumn{2}{|c|}{ Questions } \\
\hline ID & Questions \\
\hline Q1 & How did you like the prototype system? \\
\hline Q2 & $\begin{array}{l}\text { How did you like the product listing of the beta } \\
\text { version of the system? }\end{array}$ \\
\hline Q3 & $\begin{array}{l}\text { Did you find the product catalogue section inter- } \\
\text { esting? }\end{array}$ \\
\hline Q4 & Did you find the system fast? \\
\hline Q5 & Do you find the interface easy to use? \\
\hline
\end{tabular}

2) Responses from Testing: As shown in Fig. 14 the answers made from the Q1 testing responded that the system prototype seems good to $73 \%$ and those who think it is bad is $28 \%$, in Q2 responded that the system version listing is good $71 \%$ and bad $29.4 \%$, in Q3 $58.8 \%$ think that the product catalogue is good, maybe $33.3 \%$ and bad $7.8 \%$ in Q4 they answered how they thought the operation of the system where they thought it was good $78.4 \%$ and bad $24.6 \%$, in the last Q5 they answered how they thought the management of the prototype where they thought it was good $60.8 \%$, maybe $31.4 \%$ and bad $7.8 \%$ all this was done according to the response of all customers who took the survey. 


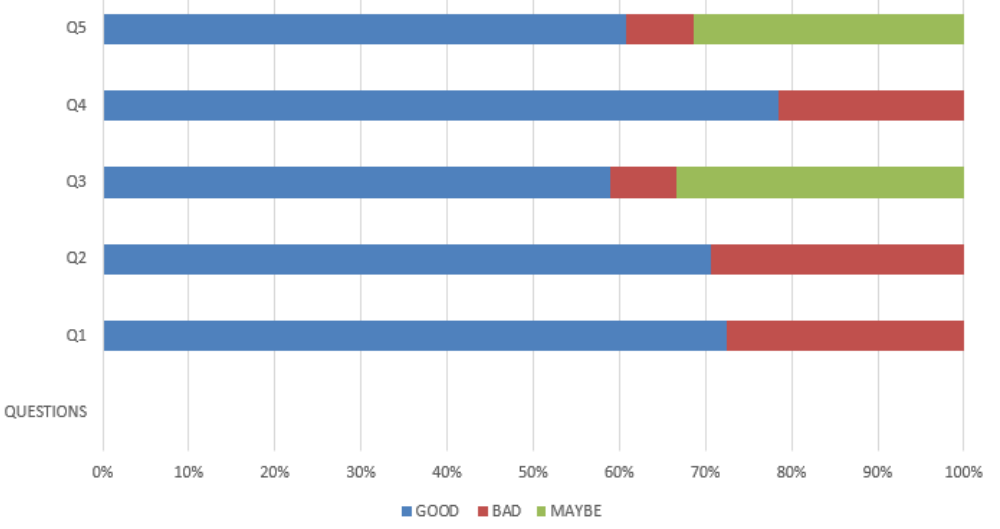

Fig. 14. Testing Response.

\section{E. Proposal for Digital Marketing}

In this digital marketing proposal it indicates the fundamental tools to attract new users in a short time, being effective for the brand recognition of companies.

1) Search Engine Optimization (SEO): The SEO has a fast search engine, allowing to identify our website that is on any server, helping to generate more visits, having a greater reach so that people can view any business they have online. Thus becoming an attractive information system at the academic level, as well as at the professional level [31]. Counting with different techniques for its use: page optimization, facilitates the search through tags and keywords; creation of links through the references of links, these are generated through backlinks; content creation, this technique is important because through SEO, allows us to create high quality content, gain links this technique applies to new and interactive content already created that is used through links on websites .

2) Search Engine Marketing (SEM): It works by searching for keywords to have a better visibility on websites, one of the problems of SEM for its use has to have a staff in charge with experience so that its management is correct. Several companies use SEM for their advertising budget and for other areas of the companies, thus being used in electronic marketplaces to improve search and to attract more sponsors [32]. Bearing in mind that in order to handle SEM, it is not necessary to be a large company as nowadays small companies are also starting to use Search Engine Marketing for their own benefit.

3) Facebook $A D S$ : It is a system that allows you to promote a Facebook page, website or application, to publish the promotion of the ad must be paid, these ads offers tools for creating campaigns as well as using graphics formats, videos and images. This system is effective to gain new users on Facebook for any type of business [33].

4) Email Marketing: Email marketing is used for customer to customer dialogue, leveraging the potential for cross-selling and up-selling. It is now widely used in the workplace as it can help us to get more customers in more effective ways; these can be used in e-commerce for their operation [34].

5) Google Analytics: It allows us to measure time, budget and collect data from our website users through web analytics
[35], this will help us to analyse user behaviours and obtain useful marketing intelligence .

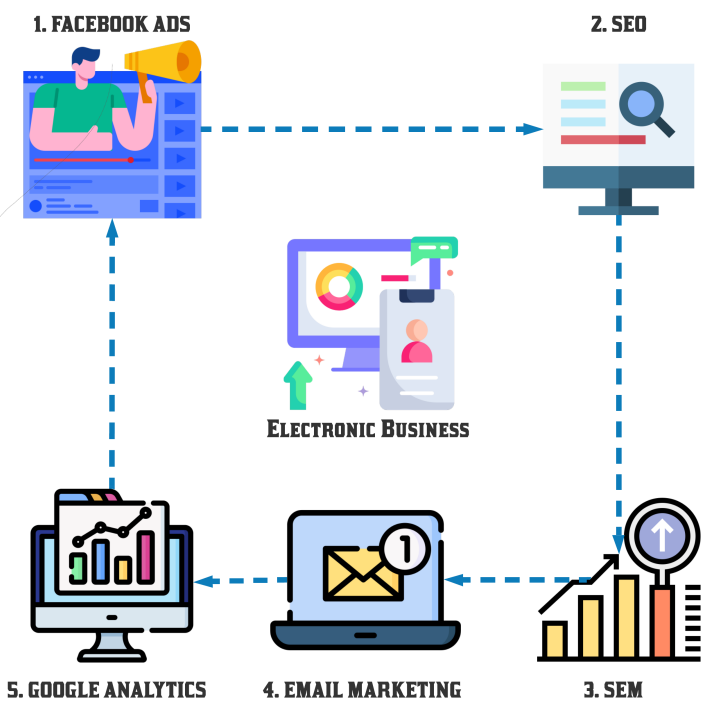

Fig. 15. Digital Marketing Proposal Template.

In Fig. 15, shows the digital marketing model, once the e-business is posted on the web, it will start with the first stage which is Facebook ADS that will be responsible for advertising for brand recognition or e-business of the company at the Peruvian level. In the second stage will be the SEO as it will help us to position ourselves on the Web, through organic searches, ie, are free and appear within the first 3 in the search of google.the third stage will be the SEM; will serve to obtain greater visibility through various advertising campaigns to itself position the e-business in the first place, SEO will help to position itself in the long term and the SEM in the short term. Once the records of new users in the e-business are obtained in the database, their emails will be requested in order to follow up on the fourth stage, which is Email Marketing, to inform the services of the business. The last stage will use Google Analytics to analyse the performance of the system or social networks.

\section{CONClusions And Future Work}

The e-business was developed in the Peruvian company Domínguez proposing the use of digital marketing to obtain a larger clientele, as well as having different tools to generate appropriate advertising and measure the performance of the web platform. The methodology is the most essential part of the work helping us to innovate and manage the development of the e-business. It would be of great help to use these methods for Peruvian businesses in times of pandemic or in any health situation as it is an effective strategy to generate a great impact in any department or district of Peru, as well as to position MSEs or SMEs in the market. For future research, the development of the proposed model of digital marketing is proposed, taking into account that augmented reality can also be implemented to improve the visualisation of the state of the products in real time, as well as to have greater confidence in the customers. It is also suggested that you can implement Web Scraping to know the weaknesses of our system and not 
suffer data loss or theft of information in the long term, as also serves to obtain price information from the database of the competition.

\section{ACKNOWLEDGMENT}

This work was sponsored by the University of Sciences and Humanities and the research direction. To acknowledge Dr. Carlos Sotomayor Beltrán for the suggestions in the article.

\section{REFERENCES}

[1] S. Hussain, A. Sohail, C. Yu, S. Manzoor, and A. Zahid, "China-pakistan economic corridor (cpec's) socioeconomic impacts on pakistan," International Journal of Management \& Entrepreneurship Research, vol. 2, no. 6, pp. 416-436, 2020.

[2] M. Shafi, J. Liu, and W. Ren, "Impact of covid-19 pandemic on micro, small, and medium-sized enterprises operating in pakistan," Research in Globalization, vol. 2, p. 100018, 2020.

[3] T. Erdem, "Competitiveness of dried sector: A case study of world and turkey," Agricultural Economics, vol. 66, no. 8, pp. 365-372, 2020.

[4] B. González-Bustamante, "Evolution and early government responses to covid-19 in south america," World Development, vol. 137, p. 105180, 2021.

[5] M. M. Cequea, J. M. Vásquez Neyra, V. G. H. Schmitt, and M. Ferasso, "Household food consumption and wastage during the covid-19 pandemic outbreak: A comparison between peru and brazil,' Sustainability, vol. 13, no. 14, p. 7583, 2021.

[6] T. Q. Thinh, D. A. Tuan, N. T. Huy, and T. N. A. Thu, "Financial distress prediction of listed companiesempirical evidence on the vietnamese stock market," Innovations, vol. 17, no. 2, pp. 377-388, 2021.

[7] S. P. Goldman, H. van Herk, T. Verhagen, and J. W. Weltevreden, "Strategic orientations and digital marketing tactics in cross-border e-commerce: Comparing developed and emerging markets," International Small Business Journal, vol. 39, no. 4, pp. 350-371, 2021.

[8] J. M. Málaga Arana, "Estudio para la implementación del marketing digital y el comercio electrónico en la empresa t \& c technologycel, surquillo, 2019," 2019.

[9] S. M. Maarac, Z. Filipović, and M. Eljuga, "E-commerce in trade companies during the conditions of a pandemic crisis: Case studies," EU and comparative law issues and challenges series (ECLIC), vol. 5, pp. 728-745, 2021.

[10] M. Vagner, "Digitalni marketing," Ph.D. dissertation, University of Zagreb. Faculty of Teacher Education, 2017.

[11] P. R. Marin Pumarrumi, "Dimensiones del marketing digital para incrementar las ventas de una mype del sector de servicios de seguridad integral," 2019.

[12] L. Ljubisavljević, D. Milačić, and M. Ninković, "Development of a web shop based on augmented reality," in E-business technologies conference proceedings, vol. 1, no. 1, 2021, pp. 40-43.

[13] S. Dinesh and Y. MuniRaju, "Scalability of e-commerce in the covid-19 era," International Journal of ResearchGRANTHAALAYAH, vol. 9, no. 1, pp. 123-128, 2021.

[14] R. Kamran and A. Dal Cin, "Designing a mission statement mobile app for palliative care: an innovation project utilizing design-thinking methodology," BMC Palliative Care, vol. 19, no. 1, pp. 1-6, 2020.

[15] J. Vogelzang, W. F. Admiraal, and J. H. van Driel, "Scrum methodology as an effective scaffold to promote students' learning and motivation in context-based secondary chemistry education," EURASIA Journal of Mathemathics, Science and Technology Education, vol. 15, no. 12, p. em1783, 2019.

[16] V. Gomero-Fanny, A. R. Bengy, and L. AndradeArenas, "Prototype of web system for organizations dedicated to e-commerce under the scrum methodology," International Journal of Advanced Computer Science and Applications, vol. 12, no. 1, 2021. [Online]. Available: http://dx.doi.org/10.14569/IJACSA.2021.0120152

[17] A. Tupia-Astoray and L. Andrade-Arenas, "Implementation of an e-commerce system for the automation and improvement of commercial management at a business level," International Journal of Advanced Computer Science and Applications, vol. 12, no. 1, 2021. [Online]. Available: http://dx.doi.org/10.14569/IJACSA.2021.0120177

[18] J. Vogelzang, W. F. Admiraal, and J. H. Van Driel, "A teacher perspective on scrum methodology in secondary chemistry education," Chemistry Education Research and Practice, vol. 21, no. 1, pp. 237-249, 2020.

[19] J. Vrana and R. Singh, "Nde 4.0-a design thinking perspective," Journal of nondestructive evaluation, vol. 40, no. 1, pp. 1-24, 2021.

[20] M.-J. Tsai and C.-Y. Wang, "Assessing young students' design thinking disposition and its relationship with computer programming self-efficacy," Journal of Educational Computing Research, vol. 59, no. 3, pp. 410-428, 2021.

[21] Y. Zavoleas, "Patterns of nature: Bio-systemic design thinking in meeting sustainability challenges of an increasingly complex world," Developments in the Built Environment, vol. 7, p. 100048, 2021.

[22] J. Vogelzang, W. F. Admiraal, and J. H. van Driel, "Scrum methodology in context-based secondary chemistry classes: effects on students' achievement and on students' perceptions of affective and metacognitive dimensions of their learning," Instructional Science, pp. 128, 2021.

[23] M. Morandini, T. A. Coleti, E. Oliveira Jr, and P. L. P. Corrêa, "Considerations about the efficiency and sufficiency of the utilization of the scrum methodology: A survey for analyzing results for development teams," Computer Science Review, vol. 39, p. 100314, 2021.

[24] A. muayad younus Alzahawi and M. Abumandil, "Evaluating the role of scrum methodology for risk management in information technology enterprises," Journal of Information Technology and Computing, vol. 2, no. 1, pp. 1-8, 2021.

[25] T. Z. Khan, S. H. Tusher, M. Hasan, and M. Rokonuzzaman, "Tailoring scrum methodology for game development," in Advances in Computer, Communication and Computational Sciences. Springer, 2021, pp. 233-243.

[26] V. Casola, "Scrum for safety: Agile development in safety-critical software systems," in Quality of Information and Communications Technology: 14th International Conference, QUATIC 2021, Algarve, Portugal, September 8-11, 2021, Proceedings, vol. 1439. Springer Nature, 2021, p. 127. 
[27] M. K. Foster, "Design thinking: A creative approach to problem solving," Management Teaching Review, vol. 6, no. 2, pp. 123-140, 2021.

[28] D. V. Albay, Eduard M y Eisma, "Evaluación de la tarea de desempeño respaldada por el proceso de pensamiento de diseño: resultados de una verdadera investigación experimental," Social Sciences and Humanities Open.

[29] A. Carrion-Silva, C. Diaz-Nunez, and L. AndradeArenas, "Admission exam web application prototype for blind people at the university of sciences and humanities," International Journal of Advanced Computer Science and Applications, vol. 11, no. 12, 2020. [Online]. Available: http://dx.doi.org/10.14569/IJACSA.2020.0111246

[30] A. Delgado and P. Condori, "Comparative study of methods to improve administrative processes in a organization," in 2018 Congreso Internacional de Innovación y Tendencias en Ingeniería (CONIITI), 2018, pp. 1-5.

[31] R. Lui and C. H. Au, "Is educational game: Adoption in teaching search engine optimization (seo)," Journal of
Computer Information Systems, 2018.

[32] R. Aswani, A. K. Kar, P. V. Ilavarasan, and Y. K. Dwivedi, "Search engine marketing is not all gold: Insights from twitter and seoclerks," International Journal of Information Management, vol. 38, no. 1, pp. 107-116, 2018.

[33] A. L. Ortega, "Are microtargeted campaign messages more negative and diverse? an analysis of facebook ads in european election campaigns," European Political Science, pp. 1-24, 2021.

[34] V.-D. Păvăloaia, I.-D. Anastasiei, and D. Fotache, "Social media and e-mail marketing campaigns: Symmetry versus convergence," Symmetry, vol. 12, no. 12, p. 1940, 2020.

[35] S.-C. Chen, T. C.-Y. Tsao, K.-H. Lue, and Y. Tsai, "Google analytics of a pilot study to characterize the visitor website statistics and implicate for enrollment strategies in medical university," BMC medical education, vol. 20, no. 1, pp. 1-12, 2020. 